\title{
Os ciclos do presidencialismo de coalizão e seus determinantes político-econômicos ${ }^{2,3}$
}

\section{The coalitional presidentialism cycles and its political-economic determinants}

\section{Introdução}

Quais seriam os determinantes político-econômicos da instabilidade intracoalizão? Essa é a pergunta que o trabalho busca responder, com base em uma recente abordagem no estudo do sistema brasileiro. Após o surgimento do termo presidencialismo de coalizão por Abranches (1988), o debate sobre este sistema já teve diversos focos, passando pelas perspectivas negativas, com foco na instabilidade do sistema presidencial multipartidário (Mainwaring, 1993), e chegando à perspectiva sobre a formação das coalizões, estabilidade e previsibilidade do sistema (Figueiredo e Limongi, 1998) e aos padrões de comportamento presidencial e legislativo

1 Mestranda em Ciência Política na Universidade Federal de Pernambuco (UFPE). E-mail: <aline. melquiades@ufpe.br>.

2 Artigo resultante do Trabalho de Conclusão de Curso de Graduação em Ciência Política pela UFPE, orientado pelo Prof. Dr. Marcus André Melo. Agradecimentos especiais são voltados aos membros da banca: Ernani Carvalho (UFPE) e especialmente Mariana Batista (UFPE), a qual acompanhou parte do processo de elaboração do artigo. Agradeço também aos pareceristas da Revista Brasileira de Ciência Política (RBCP), colegas e professores do Departamento de Ciência Política da UFPE, pelas críticas e sugestões ao trabalho.

3 Versões similares foram apresentadas no $9{ }^{\circ}$ Congresso Latino-americano de Ciência Política da Associação Latino-americana de Ciência Política (Alacip), no painel "Executivos, Coalizões e Capacidade Decisória no Brasil" (Montevidéu, UR - julho/2017) e no Grupo de Trabalho (GT) "O Presidencialismo de Coalizão Brasileiro", do 41 Encontro Anual da Associação Nacional de Pós-Graduação e Pesquisa em Ciências Sociais (Anpocs) (Caxambu, MG - outubro/2017). 
(Amorim Neto, 2000; 2006). Em seguida, ao pork barrel politics e à importância da liderança partidária (Pereira e Mueller, 2003).

Abranches (2014) trouxe recentemente mais uma contribuição para a análise do sistema brasileiro, elaborando uma nova abordagem que se chama "ciclos do presidencialismo de coalizão". Estes ciclos, denominados centrípeto, "de ambivalência" e centrífugo, seriam determinados por conflitos intracoalizão e pela dinâmica macroeconômica e estrutural. Entretanto, o principal motor dos ciclos seria a força de atração presidencial, caracterizada pela popularidade, pela inflação e pelo crescimento econômico. Na literatura sobre parlamentarismo, a ideia da ocorrência de ciclos de vida e da relação entre estabilidade e fatores macroeconômicos e políticos não é novidade (Lupia e Strom, 2008). Na literatura sobre estabilidade política no presidencialismo, há um foco na estabilidade ministerial e na capacidade de sobrevivência do presidente no cargo (Martínez-Gallardo 2012; Carlin, Love e Martínez-Gallardo, 2015; Altman, 2000). Já Abranches (2014) aborda a força de atração presidencial ou a capacidade do presidente de aglutinar apoio, para traçar a relação entre a estabilidade da coalizão e os fatores macroeconômicos e estruturais.

Deste modo, o objetivo deste trabalho é realizar um teste das proposições de Abranches, verificando empiricamente como esses fatores da força de atração presidencial causam ou se relacionam com a estabilidade de apoio das coalizões, que é o cerne dos ciclos. Isso se faz necessário pois, como mesmo observa Abranches (2014), frequentemente as coalizões apresentam instabilidade, ou seja, configuram-se como um padrão que tem se repetido nos últimos governos pós-1988.

Para tanto, serão realizadas análises descritivas e inferenciais, com dados em painel. As variáveis mobilizadas serão disciplina legislativa da coalizão, taxa de sucesso do presidente, Produto Interno Bruto (PIB), taxa de inflação e popularidade presidencial. $\mathrm{Na}$ estatística inferencial, serão realizados modelos de regressão linear com efeitos fixos e aleatórios, de acordo com a variável dependente, 
além da abordagem GMM (Generalized Method of Moments). Este último método com o objetivo de "solucionar" o problema de endogeneidade entre crescimento econômico e estabilidade política (Alesina et al., 1996). No entanto, testes preliminares não rejeitaram a hipótese de que a variável PIB seja exógena, por isso optou-se pela utilização de ambos os métodos para análise. Além disso, os testes indicaram a utilização de diferentes modelos de acordo com a variável dependente.

Por fim, a observação dos gráficos e dos resultados dos modelos inferenciais permite que se afirme que a disciplina da coalizão configurou-se como principal variável dependente. Além disso, a variável econômica PIB apresentou os melhores resultados, confirmando a hipótese de que a diminuição desta causa instabilidade na coalizão. A causalidade para a popularidade também foi confirmada, mas apenas para a variável dependente "disciplina". Concomitantemente, a taxa de inflação apresentou resultados contraditórios, e, portanto, não foi possível confirmar sua relação com a manutenção do apoio da coalizão.

A primeira seção deste trabalho apresentará a evolução das teorias do presidencialismo de coalizão e o debate sobre aspectos da governabilidade. Uma subseção abordará a teoria dos ciclos e a estabilidade da coalizão. A segunda seção trata do debate sobre política e economia, abordando a relação endógena entre fatores econômicos e a estabilidade política. A terceira discute a metodologia e os testes estatísticos e econométricos realizados para escolha do modelo. A quarta seção aborda os resultados descritivos e inferenciais, com ambos os métodos. A quinta apresenta a discussão sobre os resultados encontrados, apontando as insuficiências e complementações à teoria. Por fim, constam as conclusões gerais.

\section{O presidencialismo de coalizão}

O termo "presidencialismo de coalizão" foi cunhado por Abranches (1988), o qual fomentou um grande debate sobre aspectos de governabilidade no presidencialismo brasileiro. O presidente 
precisa conciliar dois eixos, buscando tanto uma composição partidária majoritária quanto a representação de particularidades estaduais. Assim, em sociedades mais divididas, a formação de alianças é um requisito para a governabilidade e estabilidade institucional (Ibid.).

Mauerberg Junior, Pereira e Biderman (2015) sugerem que há quatro abordagens no estudo sobre o presidencialismo de coalizão brasileiro: a) a perspectiva que aponta as limitações do presidencialismo multipartidário; b) a abordagem sobre a construção das coalizões governamentais; c) a abordagem da gestão da coalizão; e d) a perspectiva do papel das instituições e dos líderes partidários no Congresso.

A primeira perspectiva exibe, de modo geral, uma visão negativa do presidencialismo multipartidário, apresentando-o com uma difícil combinação e comparando-o com o parlamentarismo. Essa abordagem aponta para o impasse constante nas relações entre o Executivo e o Legislativo, para a dificuldade de construção de coalizões multipartidárias estáveis, e dá preferência ao sistema presidencialista bipartidário (Mainwaring, 1993). Outra análise mostra preferência pelo sistema parlamentarista em detrimento do presidencialista, apontando que este último apresenta dificuldades devido ao mandato fixo (e às dificuldades de impeachment) e à "impossibilidade" de conciliação por múltiplos papéis na política (Linz et al., 1991).

Ainda se insere nessa abordagem Abranches (1988), que já chamava a atenção para falhas de coordenação, conflito intrapartidário e intracoalizão, que poderiam levar o sistema à fragmentação e à paralisia decisória. Assim, um alto fracionamento governamental ou uma grande coalizão concentrada seriam prejudiciais ao sistema. A solução apontada por Abranches é incluir maior número de parceiros e admitir maior diversidade ideológica, porém a probabilidade de instabilidade também aumenta. Caso haja, por exemplo, uma má distribuição de cargos e ministérios, que 
não respeite a proporcionalidade do Legislativo, poder-se-ia gerar tendências centrífugas, e uma subsequente crise de governança (Abranches, 2001 apud Tavares e Giusti, 2001).

A eficácia político-operacional da governança é determinada pela capacidade de coordenação da maioria por parte do chefe do Executivo que ocupa o centro do sistema de forças. Quando há falhas de coordenação, o sistema tende à fragmentação, podendo sofrer paralisia decisória e colapsos recorrentes de desempenho, com danos ao apoio social do governo [...]. A gestão política da coalizão precisa manter o estresse em nível aceitável e evitar que a concorrência entre os aliados leve ao colapso da aliança (Abranches, 1988, p. 77).

A segunda abordagem concerne à formação das coalizões. Figueiredo e Limongi (1998) demonstraram que o sistema brasileiro é previsível, estável e eficiente no processo decisório, com média de $89,4 \%$ de disciplina partidária. Sendo, no geral, as derrotas do Executivo creditadas à falta de coesão interna da coalizão. Além disso, mostraram como o Executivo organiza o apoio em bases partidárias, semelhante ao parlamentarismo, por meio do qual garantem o sucesso da sua agenda legislativa. Segundo eles, isso ocorre devido à centralização do processo pelo Executivo, ao poder de agenda, ao controle orçamentário, às organizações procedimentais etc.

Amorim Neto $(2000 ; 2006)$ sustenta que o comportamento disciplinado tem como contrapartida o compartilhamento de poder por meio de ministérios, respeitando critérios de proporcionalidade em relação à representação dos partidos na Câmara dos Deputados. Gamson (1961) sugeria o princípio de proporcionalidade na distribuição de ministérios (ou outros recursos) entre os participantes da coalizão, de acordo com a quantidade de assentos no Legislativo, como uma forma de 
recompensa (payoff). Assim, em consonância à Lei de Gamson (1961), Amorim Neto $(2000 ; 2006)$ formulou o índice (ou taxa) de coalescência para medir a proporcionalidade na distribuição de ministérios de acordo com a representação legislativa.

A terceira abordagem engloba estudos sobre o processo de emenda ao orçamento. A emenda ao orçamento é um fator essencial na barganha e na relação entre Executivo e Legislativo, devido ao potencial de pork barrel politics. ${ }^{4}$ Esse comportamento baseia-se na troca de apoio ao Executivo pelas emendas ao orçamento, e demonstrou ser mais efetivo do que as proposições legislativas. Entretanto, sustenta-se que é possível a coexistência de um comportamento partidário e pessoal, por meio do pork barrel (Pereira e Mueller, 2003). Outros aspectos institucionais, como as regras que regem o próprio processo legislativo, também fazem parte desta terceira abordagem, isto é, as regras e os procedimentos que definem a centralização das prerrogativas e inciativas do processo de decisão como variáveis para comportamento dos legisladores (Mauerberg Junior, Pereira e Biderman, 2015).

Para além dos trabalhos abordados na classificação sobre a gestão da coalizão, destaca-se a contribuição de Bertholini e Pereira (2017), no qual eles formulam um índice de custo de governo baseado no tamanho da coalizão, na heterogeneidade ideológica e na alocação proporcional de poder entre parceiros. Os autores defendem ainda que o gasto de recursos com aliados não significa necessariamente o apoio; entretanto, a composição da coalizão com menos parceiros, mais homogênea ideologicamente e mais proporcional no compartilhamento de poder, aumentaria o apoio legislativo ao Executivo. Raile, Pereira e Power (2011) também sustentam a utilização da distribuição de cargos e do pork barrel ${ }^{5}$ na gestão da coalizão e manutenção do apoio legislativo.

\footnotetext{
4 Uso da prerrogativa de emendas individuais ao orçamento pelos deputados com o objetivo de favorecer bases eleitorais, e, assim, maximizar as chances de reeleição.

5 Os autores citam como ferramentas ou recursos substitutos, utilizados em diferentes casos.
} 
A quarta abordagem versa sobre a liderança partidária, que é outro aspecto que afeta a governabilidade. Os líderes tanto representam uma ponte entre os parlamentares e o Executivo, quanto demonstram a importância dos partidos à arena legislativa ${ }^{6}$ (Pereira e Mueller, 2003). Por conseguinte, os líderes agem como representantes partidários no processo de barganha com o Executivo, e os estudos mostram o comportamento coeso e disciplinado de acordo com suas indicações (Figueiredo e Limongi, 1998). Miranda (2010) destaca a centralidade das lideranças partidárias para maximizar preferências de parlamentares e diminuir custos. Além disso, aborda como a mesa diretora possui grandes atribuições no processo decisório, desde a determinação da ordem do dia até o desempate de votações.

Em suma, há diversas perspectivas de análise na Ciência Política sobre o presidencialismo de coalizão, desde as que abordam seus aspectos negativos e as dificuldades do sistema em manter um nível sustentável de governabilidade, até as que o exibem como um sistema estável e previsível, em que coexistem o comportamento individual e partidário, destacando-se o papel dos líderes e a centralização do processo pelo Executivo. Um estudo recente de Abranches (2014) volta a abordar, até certo ponto, essa perspectiva próxima à negativa inicial (Abranches, 1988), defendendo a existência de ciclos de instabilidade que teriam se repetido nos governos pós-1988.

\section{Os ciclos do presidencialismo de coalizão}

A concepção da ocorrência de um ciclo de vida já foi utilizada para estudar as coalizões no parlamentarismo. Os estudos que apontam a existência de instabilidades distinguem como causas o contexto exógeno, a distribuição de recursos, as preferências políticas, as instituições, o poder de barganha e os eventos críticos.

6 Os líderes"concentram poderosas prerrogativas institucionais, tais como nomear e destituir membros e dirigentes das comissões e relatores de projetos; incluir e retirar projetos da pauta do Congresso; determinar se a sua tramitação terá caráter de urgência; orientar o voto de sua bancada no plenário; e, fundamentalmente, negociar junto ao Executivo as demandas dos parlamentares e membros de sua bancada" (Mauerberg Junior, Pereira e Biderman, 2015). 
Strøm, Müller e Bergman (2008) sustentam a existência de um ciclo de vida no parlamentarismo composto pela formação da coalizão, sua vida e morte, baseados principalmente na barganha dentro dela. Todas as fases são interconectadas, seguindo uma série cíclica de eventos que sofrem a influência das eleições anteriores e posteriores e do ambiente de incerteza. Para reduzir incertezas são realizados acordos (coalition agreements), e, além dos ministérios, podem ser realizados pactos em torno de regras em geral, tamanho de gabinete, disciplina no parlamento ou comportamento parlamentar.

No contexto presidencialista, análises semelhantes foram realizadas com países da América Latina, além do Brasil. Altman (2000) utiliza o caso uruguaio para afirmar que a probabilidade de um grupo permanecer na coalizão diminui à medida que o mandato presidencial chega ao fim, apontando a existência de ciclos de cooperação entre atores políticos. Além disso, a distribuição de portfólios, popularidade e a distância ideológica poderiam determinar a permanência na coalizão. Enquanto MartínezGallardo (2012) estuda o que causa deserção do governo e aponta que legislaturas efetivas, altas taxas de aprovação presidencial e disciplina contribuem para a estabilidade do governo, pois dariam incentivos ao presidente para manter compromissos com os partidos em troca de apoio, Carlin, Love e Martínez-Gallardo (2015) destacam que uma boa condição econômica favoreceria presidentes envolvidos em escândalos. Já Acosta e Polga-Hecimovich (2011) argumentam que a coalizão tem mais probabilidade de término quando os incentivos à cooperação e os payoffs diminuem. Em geral, as coalizões tendem a ser menos duradouras quando há crise econômica medida pela taxa de inflação, pela proximidade das eleições e conflito social. Segundo os autores, a popularidade presidencial parece ter influência sobre a formação da coalizão, mas não sobre a duração dela.

A teoria dos ciclos do presidencialismo de coalizão formulada por Abranches (2014) possui alguns fatores semelhantes aos trabalhos que tratam do ciclo da vida no parlamentarismo e aos que abordam os incentivos para permanência e apoio ao presidente. 
Abranches analisa que o presidencialismo de coalizão seria composto por ciclos, gerados por conflitos intracoalizão e pela dinâmica macroeconômica e estrutural, principalmente onde se apresenta alta fragmentação partidária. Segundo ele, estes ciclos são chamados centrípeto, "de ambivalência" e centrífugo, e a lógica deles tem se repetido em vários governos, como nos de Collor, Fernando Henrique Cardoso (FHC), Lula e Dilma. ${ }^{7}$ O princípio motor dos ciclos é a força central da Presidência, característico dos sistemas presidencialistas, que faria com que todo o conflito ocorresse entre Congresso e Executivo, e, assim, a estabilidade da coalizão dependeria do poder de atração do presidente. ${ }^{8}$

Além dos sinais de enfraquecimento da Presidência, por fatores como queda na popularidade e fraco desempenho econômico, outras duas causas podem potencializar o conflito entre parceiros: a rivalidade local promovida principalmente pela disputa eleitoral em governos estaduais por parceiros de coalizão, e o surgimento e a viabilidade de alternativas de destaque para competir eleitoralmente com o presidente da República.

Segundo Abranches (2014), o ciclo centrípeto caracterizar-se-ia por um período de "lua de mel", em que a Presidência tem alta popularidade (acima de 55\%), desempenho econômico favorável, inflação estável e renda real estável ou em crescimento. Estes fatores facilitariam a adesão e a condução da coalizão, além de neutralizar a ação da oposição. Além disso, no ciclo centrípeto, a Presidência é dominante e pode preservar o núcleo do governo. Não haverá disputa nem contestação a cargos, e raras barganhas em projetos centrais do governo. O poder é relativamente compartilhado (misto de cargos e projetos), com baixa rivalidade entre parceiros, maiorias parlamentares estáveis e o efeito da fragmentação partidária sendo mitigado pela força centrípeta da Presidência. Assim, este ciclo de gestão seria facilitado pelo ambiente e poder de atração do presidente.

\footnotetext{
7 Fenando Collor de Melo (1990-1992), Fernando Henrique Cardoso (1995-2002), Luiz Inácio Lula da Silva (2003-2010) e Dilma Rousseff (2011-2016).

8 Segundo Abranches (2014), baseado em aspectos como popularidade presidencial, desempenho econômico e inflação.
} 
O ciclo de ambivalência pode acontecer em caso de crise decorrente de corrupção que atinja o núcleo do governo ou por alta da inflação e queda na renda real. Também se caracterizaria pela diminuição da popularidade presidencial, o que faz diminuir sua força de atração, e, assim, aumenta a rivalidade entre parceiros. Deste modo, há uma maior dificuldade na obtenção de maiorias parlamentares, fruto de pontos não negociáveis entre parceiros da coalizão. A oposição passa a ganhar cada vez mais força, com a diminuição da atração presidencial.

Chega-se, por fim, ao ciclo centrífugo (caso não haja mudança no ambiente político-econômico). Neste, a popularidade da Presidência tem sinal negativo e a "avaliação regular" não passa dos $20 \%$. A liderança presidencial e o núcleo do governo passam a ser contestados e forças que antes eram alinhadas ao governo passam a apoiar novas lideranças que surgem. A oposição torna-se mais contundente, com o "apoio das ruas". Assim, há uma paralisia decisória que leva a uma crise de governança.

\section{Política e economia}

É universalmente reconhecida a relação íntima entre a política e a economia. Diversos trabalhos, como os citados anteriormente, trazem de várias maneiras a relação ou causalidade entre variáveis políticas e econômicas. Segundo Borsani (2003), de modo geral, essa inter-relação pode ser definida de duas formas: por um lado, a situação econômica influencia as decisões eleitorais em um sentido de aprovação ou desaprovação do governo que, por conseguinte, determina as políticas que serão mantidas pelo governo, configurando a função de popularidade e o estudo dos determinantes do voto. Contudo, o governo define objetivos e medidas, e, deste modo, interfere na situação da economia, configurando a função de reação e o estudo dos determinantes das ações governamentais e resultados econômicos.

Para além da relação estabelecida pela teoria dos ciclos político-econômicos para o comportamento de variáveis e para 
a manipulação destas com fins eleitorais, alguns estudos tratam da relação entre instabilidade política e crescimento econômico, em que, de forma geral, a primeira afeta a segunda. Apesar desses estudos, é reconhecido o problema de endogeneidade dessa relação, como apontam Alesina et al. (1996, p. 6): "even if it is true that a high propensity of having frequent government changes reduces growth, it may also be the case that low growth increases the probability of a government change". Já Aisen e Veiga (2013) não apresentam testes para o efeito do crescimento econômico sobre a instabilidade política; contudo, eles também reconhecem o problema de endogeneidade entre ambas as variáveis devido ao "feedback effect". Entretanto, ainda que, de forma geral, Alesina et al. (1996) encontrem resultados de que a instabilidade política reduz o crescimento econômico, os autores acharam resultados significativos para o coeficiente do crescimento do PIB defasado sobre mudanças no governo. Isso sugere que o baixo crescimento defasado aumenta a propensão para mudanças no governo.

Em relação à inflação, Aisen e Veiga (2006) encontraram que um maior grau de instabilidade política gera taxas de inflação mais elevadas. Segundo eles, um maior número de mudanças de gabinete ou crise do governo gera não só a instabilidade política, mas também a variabilidade da política econômica, uma vez que cada novo gabinete pode ter um novo conjunto de preferências em relação aos níveis de inflação e desemprego. Deste modo, faz-se necessário um aprofundamento nos estudos do efeito do crescimento econômico (medido pelo PIB) sobre a instabilidade política, uma vez que os estudos que traçam a relação inversa não descartam a existência da direção de causalidade verificada neste trabalho, e até mesmo obtêm resultados significativos quando o testam.

\section{Metodologia}

Diante de todo o exposto, questiona-se: quais os determinantes político-econômicos da instabilidade intracoalizão? A estabilidade da coalizão pode ser definida de diversas formas; entretanto, este 
trabalho objetiva a realização de um teste empírico do que Abranches propôs. Portanto, essa estabilidade seria determinada pela força de atração presidencial, ou seja, pela capacidade do presidente de aglutinar a coalizão em torno de si (ou o apoio desta). Por isso, a variável dependente utilizada como proxy para essa força de atração (e, portanto, a estabilidade) será a disciplina legislativa da coalizão e a taxa de sucesso do presidente/coalizão. As variáveis independentes mobilizadas são os fatores da força de atração presidencial: a taxa de inflação, o PIB e a popularidade presidencial. A taxa de coalescência é incluída para análise descritiva. As descrições e fontes das variáveis estão apresentadas no quadro 1.

Os dados utilizados estão organizados em painel, já que permite a observação em corte transversal e em séries temporais. Entre as vantagens do modelo em painel, estão: maior número de observações, maior variabilidade dos dados, redução de colinearidade entre variáveis explicativas e melhoria na inferência em relação à utilização isolada com dados em cross-section ou time series (Gujarati e Porter, 2011; Wooldridge, 2006; Hsiao, 2007). O recorte temporal utilizado é 1995 a 2014, englobando os governos de FHC, Lula e o primeiro mandato de Dilma. A unidade temporal será gabinete presidencial/trimestre, para viabilizar a verificação da instabilidade dentro de cada mandato.

Quadro 1 - Descrição das variáveis

\begin{tabular}{c|c|c}
\hline Variável & Descrição & Fonte \\
\hline Disciplina & Média da disciplina da coalizão no período (trimestral) & Cebrap \\
\hline Sucesso & $\begin{array}{c}\text { Média da taxa de sucesso do presidente para projetos apre- } \\
\text { sentados pela coalizão no período (trimestral) }\end{array}$ & Cebrap \\
\hline
\end{tabular}




\begin{tabular}{c|c|c}
\hline \multirow{2}{*}{ PIB } & $\begin{array}{c}\text { Taxa de variação do PIB real trimestral em relação ao mes- } \\
\text { mo período do ano anterior (ref. 2010) }\end{array}$ & IBGE \\
\hline Log inflação & Logaritmo (base 10) da média da taxa de inflação no período (trimestre) - IPCA & IBGE \\
\hline Log inflação12 & Log (base 10) da taxa de inflação acumulada nos últimos 12 meses - IPCA & IBGE \\
\hline Ruim & Porcentagem de avaliações "ruim/péssimo"em pesquisa & CNI/lbope \\
\hline Líquida & Porcentagem da popularidade líquida medida pela subtração & CNI/lbope \\
\hline Coalescência & Taxa de coalescência das coalizões positivas pelas negativas (ótimo - ruim) & $\begin{array}{c}\text { Inácio e Rezende } \\
\text { (2015); calculado como } \\
\text { Amorim Neto (2000) }\end{array}$ \\
\hline
\end{tabular}

Elaboração própria.

Em suma, o trabalho visa à realização de um teste empírico da relação estabelecida por Abranches (2014). Assim, as hipóteses formuladas e apresentadas no quadro 2 sintetizam o que Abranches aponta como determinantes da força de atração presidencial. $\mathrm{O}$ mecanismo causal da hipótese $1 \mathrm{a}$, a respeito da variação do PIB, é que, além da própria situação do parlamentar ser afetada, a do eleitor também será, e, assim, o deputado pode considerar o impacto eleitoral de apoiar um presidente com baixa capacidade de manejo da economia. Mecanismo semelhante encontra-se na hipótese $1 \mathrm{~b}$, pois, além do histórico brasileiro, a taxa mais alta da inflação pode afastar o apoio da coalizão, à medida que os congressistas podem achar que o presidente não tem capacidade de equilibrar a economia. Já a popularidade baseia-se em um argumento vote-seeking, devido ao fato de o deputado poder justificar a ausência de apoio em decorrência da avaliação da população sobre o desempenho do presidente, considerando, assim, a imagem e as possibilidades de reeleição, ao recusar apoio a um presidente com baixa popularidade. 
Quadro 2-Hipóteses

\begin{tabular}{|c|c|c|}
\hline Hipótese & Relação & Direção esperada \\
\hline Hipótese 1a & $\begin{array}{l}0 \text { crescimento do PIB causa menor } \\
\text { instabilidade na coalizão. }\end{array}$ & $\begin{array}{l}\text { † PIB } \\
\text { T Disciplina/sucesso }\end{array}$ \\
\hline Hipótese 1b & $\begin{array}{l}\text { Uma maior taxa de inflação causa } \\
\text { maior instabilidade na coalizão. }\end{array}$ & $\begin{array}{l}\text { TInflação } \\
\text { †isciplina/sucesso }\end{array}$ \\
\hline Hipótese 2 & $\begin{array}{l}\text { A redução da popularidade do(a) presidente } \\
\text { causa instabilidade na coalizão. }\end{array}$ & $\begin{array}{l}\text { TRuim } \$ \text { Disciplina/sucesso } \\
\text { Top. líq. Disciplina/sucesso }\end{array}$ \\
\hline
\end{tabular}

Fonte: Teoria dos ciclos (Abranches, 2014).

Elaboração própria.

Os indicadores da economia mostram ao eleitor a competência e a performance governamental, e, por isso, poderiam influenciar na aprovação presidencial (Anderson, 2000; Lewis-Beck, 1988 apud BernhardeLeblang, 2008), gerando um problemademulticolinearidade. Entretanto, os valores VIF (Variance Inflation Factor) ficaram em torno de 1 , indicando ausência de multicolinearidade entre as variáveis. $\mathrm{O}$ teste de heterocedasticidade indicou a necessidade de utilização de erro-padrão robusto. E os testes de estimação de modelo para regressão com dados em painel indicaram a utilização de efeitos fixos para a variável disciplina e efeitos aleatórios para a variável sucesso.

Como já explicado em seção anterior, o PIB e a inflação deveriam ser considerados como endógenos devido à simultaneidade (feedback effect). Entretanto, os testes realizados não rejeitaram a hipótese nula de que o regressor PIB 10 seria exógeno. Ainda assim, diante do consenso demonstrado de que ambos têm uma relação endógena, não se descarta completamente a presença do problema de endogeneidade. Além disso, podemos considerar o feedback ao constatarmos o desconhecimento sobre qual crise origina a outra. Por isso, optou-se pela utilização do método GMM para lidar com a endogeneidade. Por conseguinte, diante dos resultados expostos, serão apresentados dois métodos de estimação. O primeiro será subdividido em um modelo linear com efeitos fixos para a variável disciplina, e um modelo linear com efeitos aleatórios para a variável sucesso. O segundo método de estimação será o GMM para ambas as variáveis. 


\section{Resultados}

A taxa de coalescência sempre foi um fator importante na explicação sobre o funcionamento do presidencialismo de coalizão, mas, devido à forma como os dados estão organizados, não foi possível incluí-la na análise de regressão. Entretanto, o gráfico 1 apresenta uma análise descritiva da média da disciplina e do sucesso para cada presidente, de acordo com o nível de coalescência. Oíndice de coalescência ${ }^{9}$ presente na amostra varia de .46 a $.64 .{ }^{10}$ Dividiu-se a amostra pela metade utilizando a distribuição percentil, a partir da mediana .59. O gráfico mostra que a média da disciplina da coalizão é maior se a coalescência está acima de .59 para todos os presidentes, principalmente no governo Dilma. O mesmo não acontece para variável sucesso, que apresenta tendências diferentes. Esse resultado corrobora trabalhos anteriores que utilizam a coalescência como fator explicativo para o apoio da coalizão ao presidente (Amorim Neto, 2000; 2006; Bertholini e Pereira, 2017).

Gráfico 1 - Média da disciplina e sucesso por presidente e nível de coalescência

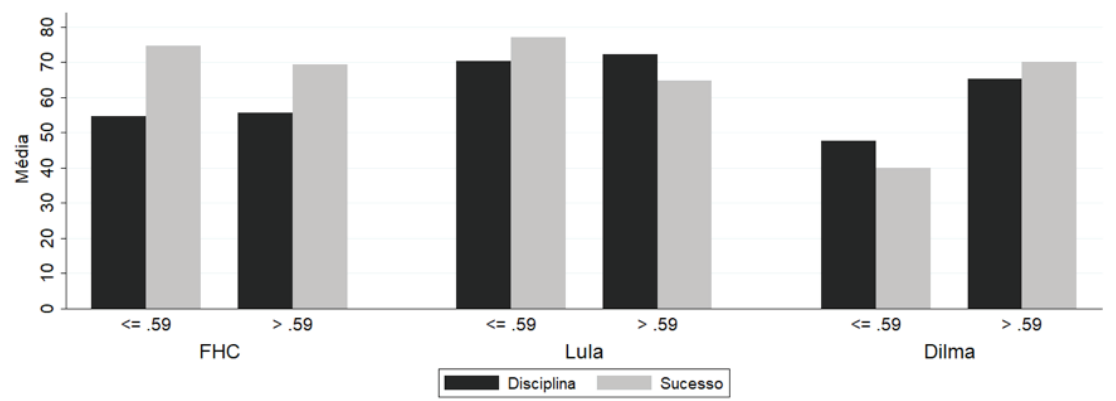

Elaboração própria.

9 Segundo Amorim Neto (2000, p. 5), "o índice varia de zero (nenhuma correspondência entre a taxa de recompensas ministeriais e a porcentagem de cadeiras) a 1, número que define o limite superior de correspondência perfeita entre cotas ministeriais e pesos legislativos dos partidos". Assim, quanto mais próximo de 1, mais coalescente.

10 Sendo .46 em FHC II 2 (segundo gabinete no segundo mandato de FHC em 2002), e .64 em FHC II 1 (primeiro gabinete no segundo mandato de FHC entre 1999 e início de 2002). 
As correlações com as variáveis independentes foram fracas, porém significativas com a variável disciplina. Já a variável sucesso apresentou correlações muito baixas, que não foram significativas. O coeficiente de correlação da disciplina com o PIB foi 0,34, com o $\log$ da inflação nos últimos 12 meses de -0,23, e com as variáveis de avaliação ruim e líquida de, respectivamente, -0,31 e 0,33. O gráfico 2 exibe a dispersão das variáveis independentes em relação à taxa de disciplina. Apesar de serem fracas, todas as correlações da variável disciplina apresentaram tendência de acordo com a teoria, enquanto a variável sucesso apresentou a correlação em consonância com a teoria apenas para o PIB.

Gráfico 2 - Dispersão da variável disciplina com as variáveis independentes, respectivamente PIB, log da inflação e \% de avaliações "ruim"
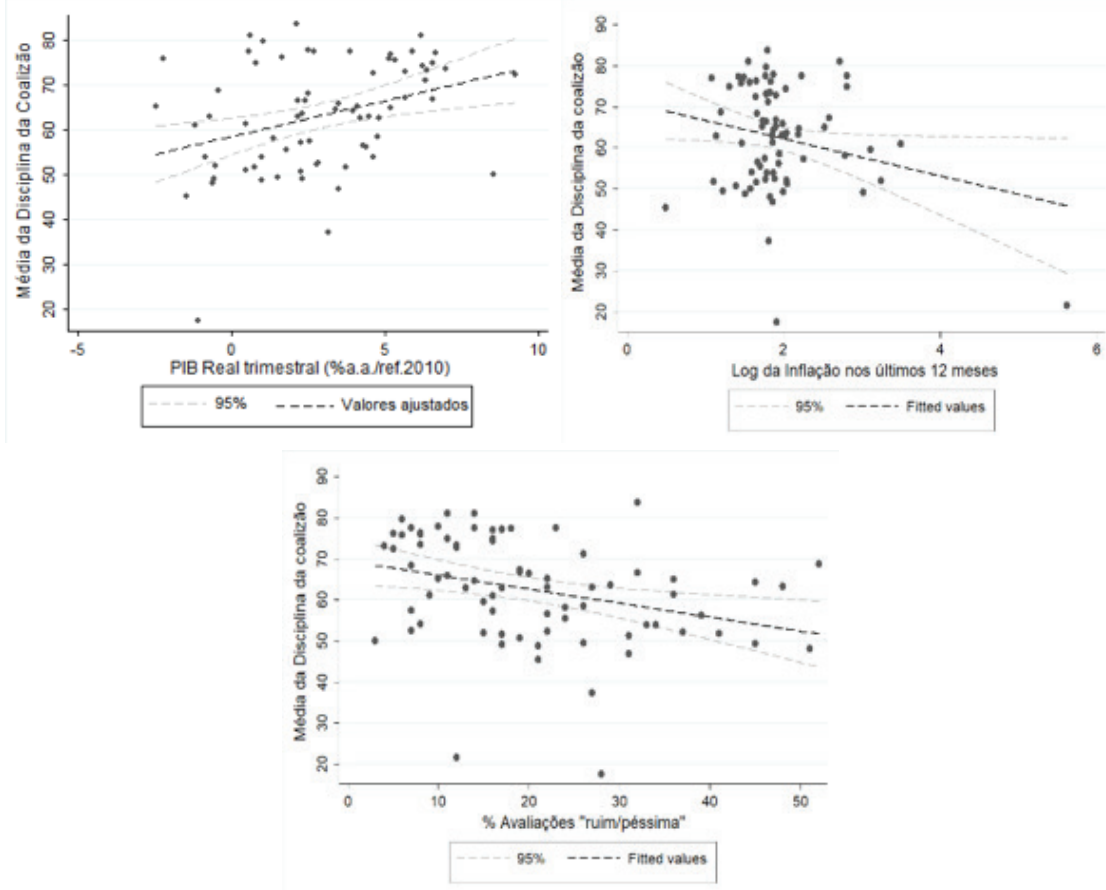

Elaboração própria. 
Nos gráficos de linha apresentados a seguir, pode-se notar, de forma clara, a mudança das principais variáveis durante os trimestres. O gráfico da variável sucesso exibe uma grande variação (gráfico 3), com comportamento semelhante ao movimento de onda e quebras de tendência visíveis, principalmente, no primeiro trimestre de quase todos os anos. Porém, os picos mais baixos apresentam-se nos anos de 2001, 2010 e 2014, ou seja, em anos de eleição e fim de mandato, ou próximo a esses.

Gráfico 3 - Média trimestral da taxa de sucesso do presidente para projetos apresentados

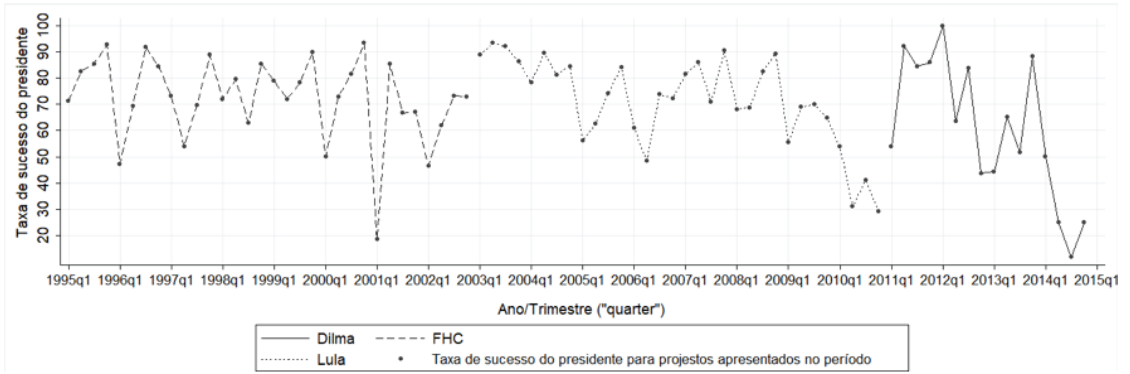

Elaboração própria.

Durante o governo FHC, notam-se pontos baixos em todas as coalizões, exceto na última, em FHC II 2, que apresenta sucesso sempre acima de $60 \%$. Os pontos mais baixos mostram-se no final de FHC I 1 (1996q1); no meio de FHC I 2 (1997q2); e no meio e no final de FHC II 1 (2000q1, 2001q1 e 2002q1). Uma possível causa para a queda em 2001 seria a "crise do apagão" que ocorreu neste período. Durante o governo Lula, os pontos mais baixos ocorreram em Lula I 3 (2005q1), Lula I 5 (2006q2), Lula II 2 (2009q1), e uma tendência clara de queda na última coalizão (Lula II 3), atingindo os pontos mais baixos nos últimos trimestres de 2010. Apesar de não estar incluída na análise, não se pode deixar de ressaltar o possível efeito do escândalo do mensalão, que ocorreu entre 2005 e 2006, sobre o sucesso do presidente. No governo Dilma há um crescimento 
no início do mandato, com quebra na primeira mudança de coalizão (2012q2), e queda em 2012q4 e 2013q1. No final de 2013 apresenta-se mais um leve crescimento, e, em seguida, volta à tendência de queda ainda no final de 2013 e início de 2014, em que se atinge o ponto mais baixo com menos de $20 \%$ de sucesso (2014q3). É importante notar que a queda coincide com o surgimento e a intensificação do escândalo de corrupção da Petrobras.

Gráfico 4 - Média trimestral da taxa de disciplina da coalizão

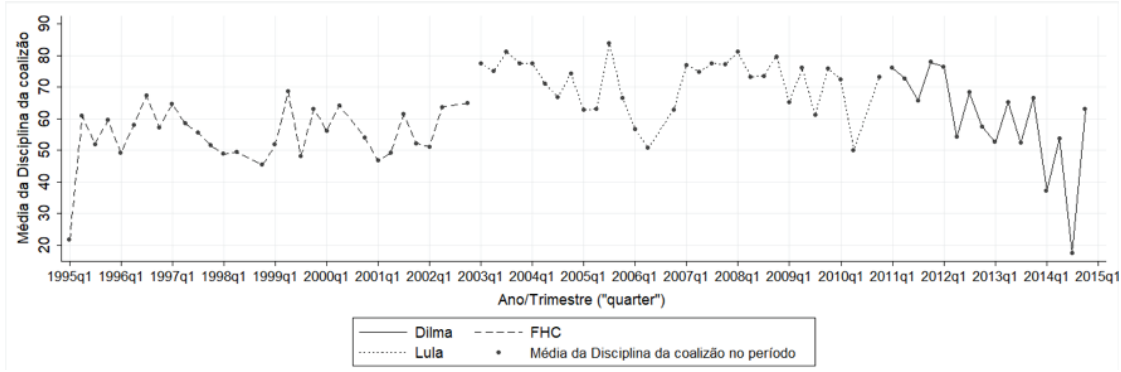

Elaboração própria.

O gráfico de linha da disciplina (gráfico 4), referente a todos os presidentes, apresentado acima, possui padrão de ondas semelhante ao de sucesso. Para o governo FHC, o ponto mais baixo dá-se no primeiro trimestre de seu mandato. Apesar da variação e de alguns pontos baixos no primeiro trimestre de 1996, último trimestre de 1998 e primeiro de 2001, não há outras grandes quebras, mantendo-se uma média de 54,98\%. Durante o governo Lula, a disciplina mostra-se alta no início, com queda no segundo trimestre de 2006 e 2010. Apesar disso, a disciplina mantém-se alta, com média de 71,13\%. Já no governo Dilma, a disciplina inicia em alta e entra em leve queda durante todo o mandato, com algumas variações e média de $59,78 \%$. No primeiro e terceiro trimestres de 2014 encontram-se os pontos mais baixos, chegando a menos de $20 \%$. Semelhante à taxa de sucesso, há tendências de queda em períodos próximos ou durante as eleições, e em períodos em que ocorreram escândalos políticos. 
O gráfico 5 apresenta a distribuição da popularidade trimestral por presidente, com alguns pontos coincidentes em relação ao sucesso e à disciplina. Para FHC, destaca-se o período a partir de 1999 até o final do mandato, quando a avaliação negativa ultrapassa a positiva, e, consequentemente, a popularidade líquida torna-se negativa. $\mathrm{O}$ governo Lula permanece com variação até o terceiro trimestre de 2005, quando apresenta popularidade líquida negativa de $-3 \%$, durante dois trimestres consecutivos. Após esse período, sua popularidade volta a subir, atingindo $80 \%$ de avaliações positivas. Abranches (2014) aponta que Lula passa pelo período de ambivalência, mas se recupera, principalmente devido à sua popularidade. Já no governo Dilma, a popularidade permanece alta até o primeiro trimestre de 2013, quando passa a cair, atingindo popularidade líquida de $-2 \%$ no segundo trimestre de 2014 .

Gráfico 5 - Popularidade presidencial (avaliações "ruim" e popularidade líquida)

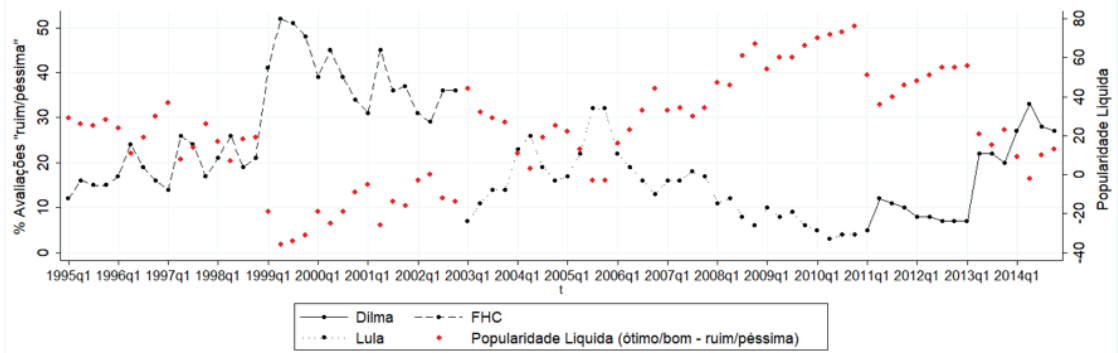

Elaboração própria.

A variação do PIB real trimestral é apresentada no gráfico de linha (gráfico 6). Em geral, pode-se notar alguns pontos semelhantes de quebra de tendência e queda nos indicadores, assim como ocorreu com o sucesso e a disciplina. Durante o governo FHC, a variação do PIB atingiu valores negativos no último trimestre de 1995, 1998 e 2001. O governo Lula apresentou, em geral, uma variação grande, mas positiva até o terceiro trimestre de 2008, quando inicia o período de queda, chegando ao ponto mais baixo no primeiro trimestre de 2009 . 
Já no governo Dilma, há uma clara queda na taxa de variação do PIB, e, após um breve período de crescimento, atinge-se o ponto mais baixo no primeiro trimestre de 2014. O gráfico 7 apresenta o gráfico de linha para inflação, exibindo a média da taxa no período e o acumulado nos últimos 12 meses. Exceto pelo início do mandato FHC até 1997, e um período entre 2002 e 2003, não há grandes quebras na taxa de inflação. A alta no início da amostra deu-se em herança do governo Collor, e por um período de adaptação à nova moeda (o Real), que estabilizou a inflação no governo FHC. Nota-se que ela possui uma variação muito baixa, o que pode ser um indicativo dos resultados das correlações e regressões.

Gráfico 6 - Variação do PIB real trimestral (\% a.a./ref. 2010)

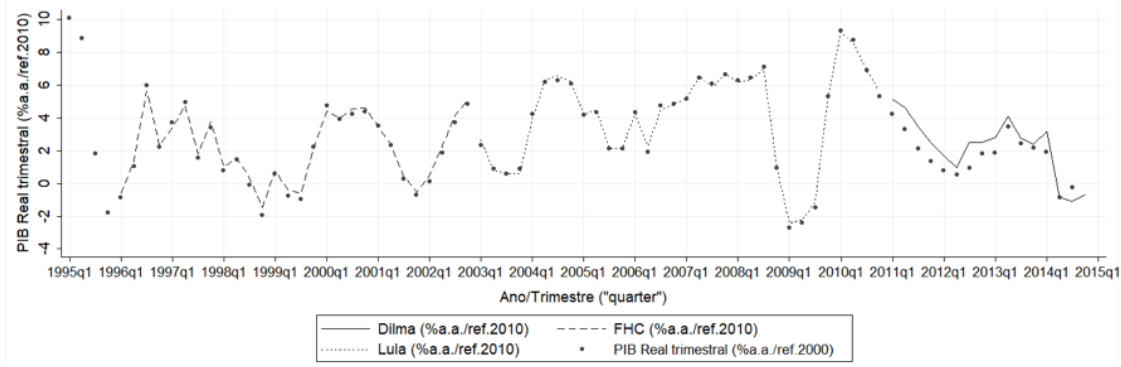

Elaboração própria.

Gráfico 7 - Média da taxa de inflação no período (IPCA)

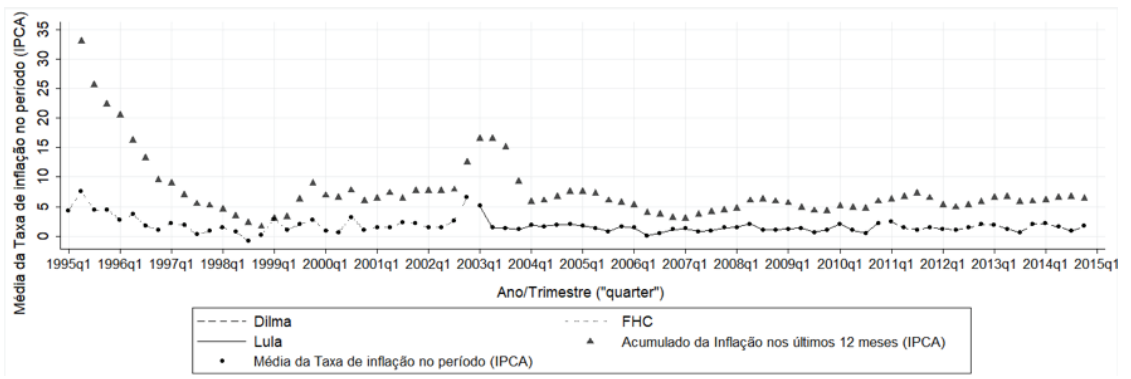

Elaboração própria. 
A tabela 1 apresenta os resultados dos modelos com efeitos fixos e aleatórios ${ }^{11}$ da regressão linear para dados em painel. Podemos inferir, pela observação, que a variável PIB possui um efeito significativo sobre a disciplina, chegando ao nível de confiança de $95 \%$. Ou seja, existe uma probabilidade de apenas $5 \%$ a $10 \%$ do impacto do PIB ser devido ao acaso. O PIB ainda foi estatisticamente significativo e com maior impacto em relação ao sucesso (modelo 5). As variáveis de popularidade e inflação apresentaram resultados significativos em apenas um modelo cada (2 e 5, respectivamente), e ambos estavam na direção contrária da esperada. Entretanto, esse resultado pode ser observado após a inclusão de variáveis defasadas, o que pode ter enviesado as estimativas. Nos modelos 3 e 6 apresentam-se as estimativas apenas com variáveis defasadas, porém nenhuma se mostrou estatisticamente significativa.

Tabela 1 - Determinantes da instabilidade (disciplina/sucesso) com método de regressão linear para dados em painel

\begin{tabular}{|c|c|c|c|c|c|c|}
\hline & \multicolumn{3}{|c|}{ Disciplina } & \multicolumn{3}{|c|}{ Sucesso } \\
\hline & Modelo 1 & Modelo 2 & Modelo 3 & Modelo 4 & Model0 5 & Modelo 6 \\
\hline PIB & $\begin{array}{c}.5^{*} \\
(.276)\end{array}$ & $\begin{array}{l}.861^{* *} \\
(.358)\end{array}$ & - & $\begin{array}{c}1.18 \\
(.919)\end{array}$ & $\begin{array}{l}1.88^{*} \\
(.973)\end{array}$ & - \\
\hline Log inflação12 & $\begin{array}{c}4.69 \\
(2.86)\end{array}$ & $\begin{array}{l}6.25 \\
(7.9)\end{array}$ & - & $\begin{array}{l}-2.2 \\
(3.4)\end{array}$ & $\begin{array}{c}7.86^{* *} \\
(3.9)\end{array}$ & - \\
\hline Ruim & $\begin{array}{c}.261 \\
(.189)\end{array}$ & $\begin{array}{l}.358^{* *} \\
(.152)\end{array}$ & - & $\begin{array}{l}.275 \\
(.38)\end{array}$ & $\begin{array}{c}.519 \\
(.604)\end{array}$ & - \\
\hline L.PIB & - & $\begin{array}{l}-.3 \\
(.637)\end{array}$ & $\begin{array}{c}.335 \\
(.615)\end{array}$ & - & $\begin{array}{l}-1.05 \\
(.826)\end{array}$ & $\begin{array}{l}-.098 \\
(.931)\end{array}$ \\
\hline L. inflação12 & - & - & $\begin{array}{c}4.9 \\
(6.31)\end{array}$ & - & - & $\begin{array}{c}4.68 \\
(6.37)\end{array}$ \\
\hline
\end{tabular}

11 Como citado na seção de metodologia, os testes indicaram a utilização do modelo com efeitos fixos para a variável disciplina, e o modelo com efeitos aleatórios para a variável sucesso. 


\begin{tabular}{c|c|c|c|c|c|c}
\hline L. ruim & - & - & $\begin{array}{l}.529 \\
(.66)\end{array}$ & - & - & $\begin{array}{c}-1.26 \\
(1.67)\end{array}$ \\
\hline \multirow{2}{*}{ L. inflação } & - & $\begin{array}{c}-2.85 \\
(3.67)\end{array}$ & $\begin{array}{c}-2.25 \\
(3.26)\end{array}$ & - & $\begin{array}{c}-2.88 \\
(2.31)\end{array}$ & $\begin{array}{c}-2.07 \\
(2.98)\end{array}$ \\
\hline \multirow{2}{*}{ L. líquida } & - & $\begin{array}{c}.096 \\
. .115)\end{array}$ & $\begin{array}{c}.212 \\
(.353)\end{array}$ & - & $\begin{array}{c}.0644 \\
(.251)\end{array}$ & $\begin{array}{c}. .674 \\
(.683)\end{array}$ \\
\hline Constante & $47.8^{* * *}$ & $40.7^{* *}$ & 37,3 & $62.7^{* * *}$ & $39.7^{* *}$ & $101^{* *}$ \\
\hline N & 71 & 55 & 55 & 76 & 60 & 60 \\
\hline R2 & .0391 & -.016 & -.0614 & - & - & - \\
\hline
\end{tabular}

Elaboração própria.

Notas: ${ }^{*}<.10 ;{ }^{* *}<.05 ;{ }^{* * *}<.01$.

Obs.: Erro-padrão robusto entre parênteses. 0"L." significa que a variável é defasada no tempo (lagged variable). VD disciplina com efeitos fixos e VD sucesso com efeitos aleatórios.

Tabela 2 - Determinantes da instabilidade (disciplina/sucesso) com método de estimação GMM

\begin{tabular}{|c|c|c|c|c|c|c|c|}
\hline & \multicolumn{4}{|c|}{ Disciplina } & \multicolumn{3}{|c|}{ Sucesso } \\
\hline & Modelo 1 & Modelo 2 & Modelo 3 & Modelo 4 & Modelo 5 & Modelo 6 & Modelo 7 \\
\hline L. disciplina & $\begin{array}{l}-.050 \\
(.2)\end{array}$ & $\begin{array}{l}-.038 \\
(.202)\end{array}$ & $\begin{array}{l}-.099 \\
(.223)\end{array}$ & $\begin{array}{l}-.149 \\
(.168)\end{array}$ & - & - & - \\
\hline L. sucesso & - & - & - & - & $\begin{array}{l}.167 \\
(.236)\end{array}$ & $\begin{array}{l}.184 \\
(.223)\end{array}$ & $\begin{array}{c}.141 \\
(.242)\end{array}$ \\
\hline PIB & $\begin{array}{c}.265 \\
(.348)\end{array}$ & $\begin{array}{l}.0103 \\
(.313)\end{array}$ & $\begin{array}{c}.1 .14^{* * * *} \\
(.423)\end{array}$ & $\begin{array}{l}.79^{*} \\
(.42)\end{array}$ & $\begin{array}{c}1.54 \\
(1.41)\end{array}$ & $\begin{array}{c}1.22 \\
(1.29)\end{array}$ & $\begin{array}{l}1.67^{* *} \\
(.578)\end{array}$ \\
\hline Ruim & - & $\begin{array}{l}-.26^{*} \\
(.151)\end{array}$ & - & $\begin{array}{l}.077 \\
(.22)\end{array}$ & $\begin{array}{c}.387 \\
(.274)\end{array}$ & - & - \\
\hline Líquida & $\begin{array}{l}.148^{* *} \\
(.059)\end{array}$ & - & - & - & - & $\begin{array}{l}-.202 \\
(.262)\end{array}$ & $\begin{array}{l}-.394 \\
(.265)\end{array}$ \\
\hline
\end{tabular}




\begin{tabular}{|c|c|c|c|c|c|c|c|}
\hline Log inflação & $\begin{array}{l}4.85^{* *} \\
(1.97)\end{array}$ & - & $\begin{array}{l}5.16^{* *} \\
(2.07)\end{array}$ & - & - & - & $\begin{array}{c}2.6 \\
(4.77)\end{array}$ \\
\hline Log inflação12 & - & $\begin{array}{c}5.99 \\
(8.51)\end{array}$ & - & $\begin{array}{l}-.893 \\
(10.4)\end{array}$ & $\begin{array}{c}-9.97^{* * * *} \\
(2.97)\end{array}$ & - & - \\
\hline L.PIB & $\begin{array}{c}.682^{* *} \\
(.34)\end{array}$ & $\begin{array}{c}.635 \\
(.453)\end{array}$ & $\begin{array}{l}.251 \\
.(349)\end{array}$ & $\begin{array}{l}-.321 \\
(.588)\end{array}$ & $\begin{array}{c}-.261 \\
(1.32)\end{array}$ & $\begin{array}{c}-.192 \\
(1.34)\end{array}$ & $\begin{array}{l}-.723 \\
(.807)\end{array}$ \\
\hline L. ruim & - & - & $\begin{array}{c}1.57 \\
(1.15)\end{array}$ & $\begin{array}{c}-.371^{* * *} \\
(.111)\end{array}$ & - & $\begin{array}{l}-.271 \\
(.461)\end{array}$ & - \\
\hline L. líquida & - & - & $\begin{array}{l}.854^{*} \\
(.505)\end{array}$ & - & - & - & $\begin{array}{c}.187 \\
(.272)\end{array}$ \\
\hline L.L. inflação & - & - & $\begin{array}{c}.994 \\
(1.83)\end{array}$ & - & - & - & $\begin{array}{c}-7.43^{* * *} \\
(2.01)\end{array}$ \\
\hline L.L. inflação12 & - & - & - & $\begin{array}{c}1.5 \\
(9.02)\end{array}$ & - & $\begin{array}{c}-9.42^{* * *} \\
(2.89)\end{array}$ & - \\
\hline Constante & $58.4^{* * *}$ & $57.4^{* *}$ & $11.3^{* * * *}$ & $75.7^{* * *}$ & $62.7^{* * *}$ & $80^{* * *}$ & $61.9^{* * *}$ \\
\hline $\mathrm{N}$ & 51 & 51 & 51 & 51 & 61 & 61 & 59 \\
\hline Chi2 & 81.2 & 50.6 & 281 & 139 & 31.6 & 36.9 & 715 \\
\hline
\end{tabular}

Elaboração própria.

Notas: ${ }^{*}<.10 ;{ }^{* *}<.05 ; * * * 0.01$.

Obs.: Erro-padrão robusto entre parênteses. 0"L." significa que a variável é defasada no tempo (lagged variable).

A tabela 2 exibe os modelos com o método de estimação GMM. A variável dependente disciplina é apresentada nos primeiros quatro modelos. Novamente o PIB foi estatisticamente significativo (modelos 3 e 4), com um impacto de cerca de uma unidade sobre a disciplina e um nível de confiança que chega a 99\% no modelo 3. As variáveis de popularidade (ruim e líquida), apesar do baixo coeficiente, também apresentaram resultados significativos e na direção esperada. A inflação voltou a apresentar resultados estatisticamente significativos, porém na direção oposta à hipótese proposta. As variáveis defasadas do PIB e da popularidade (ruim e líquida) apresentaram impacto significativo, indicando que o 
seu valor no trimestre anterior (t-1) tem efeito sobre a taxa de disciplina. As variáveis defasadas de popularidade ( $\mathrm{t}-1)$ mostraram ainda maiores estimativas de impacto do que as mesmas em um momento $\mathrm{T}$.

As estimativas com a variável dependente sucesso são apresentadas nos modelos 5, 6 e 7. O PIB foi estatisticamente significante no modelo 7, com maior impacto do que para a disciplina. As variáveis de popularidade não apresentaram resultados significativos em nenhum modelo. Ao contrário dos achados anteriores, a inflação passou a exibir estimativas em concordância com as hipóteses propostas e com nível de significância de $1 \%$. O $\log$ da inflação acumulada nos últimos 12 meses apresentou grande impacto sobre a taxa de sucesso, com estimativa semelhante para a variável defasada, enquanto o $\log$ da média da inflação no período foi significativo apenas para trimestre anterior (defasada).

\section{Discussão dos resultados: limites e possibilidades}

Os resultados descritivos apontaram para a correlação das variáveis independentes com a disciplina, de acordo com a teoria. Do mesmo modo, evidenciou-se como as variáveis dependentes sofrem grande variação e queda, em finais de mandato e em crises ou escândalos políticos. Destacou-se como a coalescência pode ser o fator explicativo para o aumento da disciplina. Além disso, os resultados inferenciais confirmaram duas hipóteses: a hipótese 1a, em que o aumento do PIB causa diminuição da instabilidade, foi amplamente apoiada; ea hipótese 2 , em que a redução da popularidade causa instabilidade, foi confirmada, porém com algumas ressalvas. A hipótese da relação da disciplina com PIB (H1a) foi confirmada por ambos os métodos, enquanto, com a taxa de sucesso, apresentou alguns resultados significativos. A hipótese da popularidade $(\mathrm{H} 2)$, apesar de exibir um resultado contraditório no primeiro método, ${ }^{12}$

12 Aponta-se como possibilidade para esse resultado a inclusão de outras variáveis que podem ter enviesado a estimativa. 
apresentou várias estimativas significativas e condizentes com a teoria no segundo método. Assim, aponta-se a necessidade de uma investigação mais detalhada sobre esta relação. A hipótese $1 b$, em que o aumento da inflação causa maior instabilidade, apresentou resultados contraditórios e poucos foram significativos. As estimativas apenas foram significativas e na direção esperada no segundo método com a variável sucesso. Os outros resultados significativos no primeiro método e no segundo, com a variável dependente disciplina, não estavam na direção esperada pela teoria. Duas possíveis explicações são: a baixa variação dos dados e pelo efeito da inflação ser mais sentida em um curto prazo.

A perspectiva teórica dos ciclos proposta por Abranches (2014) é uma abordagem que faz sentido, principalmente com o que observamos recentemente no Brasil. Mas, além das evidências e constatações das relações propostas e da explicação sobre como ocorrem os ciclos, o autor não apresenta nenhum teste para essa perspectiva teórica. Concomitantemente, há coerência na ligação entre a estabilidade da coalizão e a força de atração presidencial; entretanto, há diversos fatores que também podem afetar a estabilidade e não foram incluídas por ele, como ideologia, capacidade do presidente, escândalos políticos, tempo de mandato, distribuição de emendas etc. Estes fatores não foram incluídos neste trabalho, pois o objetivo deste foi um teste empírico das relações propostas por Abranches. Entretanto, acredita-se que a distância ideológica, o tempo de mandato e a presença de um escândalo de corrupção influem fortemente no apoio da coalizão. Assim, à luz das perspectivas de análise do presidencialismo de coalizão (Mauerberg Junior, Pereira e Biderman, 2015) evidencia-se que Abranches (2014) encontra-se mais próximo à primeira perspectiva, apesar de não abordar a inviabilidade do presidencialismo de coalizão. Entretanto, este estudo visa apenas a um teste empírico de algumas relações propostas, e, por isso, não se insere necessariamente na mesma perspectiva. Defende-se que certa instabilidade pode ocorrer por 
choques externos ou má construção da coalizão; todavia, isso não é uma característica implícita ao sistema, pois a estabilidade é possível, como já foi evidenciado por outros trabalhos. Consequentemente, aponta-se a necessidade de maior aprofundamento nos estudos.

A escolha da disciplina da coalizão e da taxa de sucesso do presidente como proxy para a força de atração presidencial (que determina a estabilidade da coalizão), deu-se na tentativa de buscar evidenciar o apoio para além do gabinete/ministérios que fundamenta diversos trabalhos. Além disso, Abranches (2014) defende que a fragmentação partidária potencializa essa dinâmica do presidencialismo de coalizão, ${ }^{13}$ ou seja, a fragmentação dificulta a estabilidade da coalizão e a formação de maiorias. Assim, apesar da literatura apontar que é possível que governos minoritários sejam bem-sucedidos (Santos, 2003; Amorim Neto, 2006), é custoso ao governo negociar a votação de projetos ad hoc ou com a oposição, e, portanto, é interessante ao governo manter a disciplina e a base de apoio. Ou seja, não é impossível governar sem maioria, mas é favorável que haja apoio da coalizão para garantir melhor governabilidade. Sabe-se ainda que a taxa de disciplina e sucesso pode ser afetada pelo tipo de projeto votado e pela agenda de governo, e que a governabilidade dependeria da inclusão das "políticas públicas" como algo perseguido pelos partidos, como defende Santos (2003), mas a alocação de recursos orçamentários a parceiros pode ser uma forma de manter o apoio da coalizão, como aponta a literatura (Pereira e Mueller, 2003). Além disso, como os dados apresentam a disciplina e o sucesso como média trimestral, não se sabe se haveria grande ganho na inclusão do tipo de projeto. Ainda assim, defende-se a inclusão desta informação como agenda de pesquisa.

13 Pesquisa de 2015 apontou que o Brasil tem a Câmara dos Deputados mais fragmentada do mundo: Mais informações em: <http://politica.estadao.com.br/noticias/geral,brasil-tem-a-camara-maisfragmentada-em-todo-o-mundo-imp-,1631324 >. Acesso em: 18 jul. 2017. 
O objetivo do artigo foi apenas testar empiricamente as proposições de Abranches; consequentemente, estamos cientes de que há uma grande perda de poder explicativo pela não inclusão de outros fatores à estabilidade da coalizão. Ao mesmo tempo, problemas relacionados ao baixo número de observações $(n=80)$ e unidades cross-section $(\mathrm{n}=15)$ podem ter prejudicado as estimativas, tornando-as menos eficientes. Assim, levanta-se como agenda de pesquisa a maior abrangência dos dados e o aprofundamento do tema, buscando uma forma mais adequada de operacionalizar a força de atração presidencial e incluindo outros fatores causais, além do tipo de agenda/projeto.

\section{Conclusão}

Por meio deste trabalho foi possível confirmar, empiricamente, algumas das relações causais estabelecidas por Abranches (2014) em seu recente artigo sobre a ocorrência de ciclos de instabilidade. Estes ciclos teriam se repetido em todos os governos pós-1988, e são determinados por fatores políticos e econômicos. $\mathrm{Na}$ análise descritiva, a verificação dos gráficos de dispersão ofereceu uma prévia da relação entre as variáveis utilizadas: disciplina, sucesso, PIB, inflação e popularidade. A coalescência mostrou-se como um fator que pode influenciar o aumento da disciplina. E os gráficos de linha foram ainda mais importantes, à medida que foi possível perceber visualmente as tendências de crescimento e de queda das variáveis em períodos de crise política e finais de mandato.

A análise realizada a partir das regressões lineares para dados em painel e do método GMM mostrou diferenças entre os modelos, ao mesmo tempo em que revelou padrões. A variável disciplina mostrou-se mais efetiva do que o sucesso, na relação com as outras variáveis. Ambos os métodos confirmaram que a diminuição do PIB causa instabilidade política; além disso, a popularidade 
presidencial também mostrou ter uma relação causal com a disciplina. O PIB mostrou-se a variável mais eficiente e significativa. Já a inflação apresentou resultados contraditórios entre os métodos, possivelmente pelo efeito da inflação ser mais sentida em um curto prazo e pela estabilidade da taxa desde o início da década de 1990 (pouca variação).

No geral, o problema do baixo número de observações pode ter prejudicado as estimativas. Entretanto, ainda foi possível corroborar algumas das relações estabelecidas por Abranches (2014). Destacam-se, ainda, outros fatores que poderiam afetar a estabilidade da coalizão, como distância ideológica, tempo de mandato e presença de corrupção, os quais não foram incluídos na análise por se tratar de um teste empírico das proposições de Abranches. Por fim, fica aberta a agenda para aprofundamento da pesquisa em relação à coalescência e à inflação, além da inclusão de outros fatores causais não considerados por Abranches, seja com outros métodos, seja com melhoria e adequação dos utilizados neste trabalho.

\section{Referências}

ABRANCHES, Sérgio. Presidencialismo de coalizão: o dilema institucional brasileiro. Dados, v. 31, n. 1, p. 5-38, 1988.

.Osciclos dopresidencialismodecoalizão.EcopolíticaEnsaios, 2014. Disponível em: <http://www.academia.edu/6411308/Os_ Ciclos_do_Presidencialismo_de_Coaliz\%C3\%A3o>. Acesso em: 20 jun. 2015.

ACOSTA, Andrés Mejía; POLGA-HECIMOVICH, John. Coalition erosion and presidential instability in Ecuador. Latin American Politics and Society, v. 53, n. 2, p. 87-111, 2011.

AISEN, Ari; VEIGA, Francisco José. Does political instability lead to higher inflation? A panel data analysis. Journal of Money, Credit, and Banking, v. 38, n. 5, p. 1379-1389, 2006. 
How does political instability affect economic growth? European Journal of Political Economy, v. 29, p. 151-167, 2013. ALESINA, Alberto et al. Political instability and economic growth. Journal of Economic Growth, v. 1, n. 2, p. 189-211, 1996.

ALTMAN, David. The politics of coalition formation and survival in multiparty presidential democracies: the case of Uruguay, 1989-1999. Party Politics, v. 6, n. 3, p. 259-283, 2000.

AMORIM NETO, Octavio. Presidential cabinets, electoral cycles, and coalition discipline in Brazil. Dados, v. 43, n. 3, p. 479-519, 2000.

Presidencialismo e governabilidade nas Américas. Rio de Janeiro: Ed. FGV, 2006.

ANDERSON, Christopher J. Economic voting and political context: a comparative perspective. Electoral Studies, v. 19, n. 2, p. 151-170, 2000.

BERNHARD, William; LEBLANG, David. Cabinet collapses and currency crashes. Political Research Quarterly, v. 61, n. 3, p. 517-531, 2008.

BERTHOLINI, Frederico; PEREIRA, Carlos. Pagando o preço de governar: custos de gerência de coalizão no presidencialismo brasileiro. Revista de Administração Pública, early view, 2017.

BORSANI, Hugo. Eleições e economia: instituições políticas e resultados macroeconômicos na América Latina, 1979-1998. Belo Horizonte: Ed. UFMG, 2003.

CARLIN, Ryan E.; LOVE, Gregory J.; MARTÍNEZ-GALLARDO, Cecilia. Cushioning the fall: scandals, economic conditions, and executive approval. Political Behavior, v. 37, n. 1, p. 109-130, 2015.

FIGUEIREDO, Argelina; LIMONGI, Fernando. Bases institucionais do presidencialismo de coalizão. Lua Nova, v. 44, p. 81-106, 1998. GAMSON, William A. A theory of coalition formation. American Sociological Review, v. 26, n. 3, p. 373-382, 1961. 
GUJARATI, Damodar N.; PORTER, Dawn C. Econometria básica. 5. ed. São Paulo: Ed. AMGH, 2011.

HSIAO, Cheng. Panel data analysis: advantages and challenges. Test, v. 16, n. 1, p. 1-22, 2007.

INÁCIO, Magna; REZENDE, Daniela. Partidos legislativos e governo de coalizão: controle horizontal das políticas públicas. Opinião Pública, v. 21, n. 2, p. 296-335 2015.

LINZ, Juan José et al. A opção parlamentarista. São Paulo: Idesp/ Sumaré, 1991.

LUPIA, Arthur; STROM, Kaare. Bargaining, transaction costs, and coalition governance. In: STRØM, K.; MÜLLER, W. C.; BERGMAN, T. Cabinets and coalition bargaining: the democractic life cycle in Western Europe. Oxford: Oxford University Press, 2008.

MAINWARING, Scott. Presidentialism, multipartism, and democracy: the difficult combination. Comparative Political Studies, v. 26, n. 2, p. 198-228, 1993.

MARTÍNEZ-GALLARDO, Cecilia. Out of the cabinet: what drives defections from the government in presidential systems? Comparative Political Studies, v. 45, n. 1, p. 62-90, 2012.

MAUERBERG JUNIOR, Arnaldo; PEREIRA, Carlos; BIDERMAN, Ciro. The evolution of theories about the Brazilian multiparty presidential system. Journal of Politics in Latin America, v. 7, n. 1, p. 143-161, 2015.

MIRANDA, Geralda Luiza de. A delegação aos líderes partidários na Câmara dos Deputados e no Senado Federal. Revista de Sociologia e Política, v. 18, n. 37, p. 201-225 2010.

PEREIRA, Carlos; MUELLER, Bernardo. Partidos fracos na arena eleitoral e partidos fortes na arena legislativa: a conexão eleitoral no Brasil. Dados, v. 46, n. 4, p. 735-771, 2003.

RAILE, Eric D.; PEREIRA, Carlos; POWER, Timothy J. The executive toolbox: building legislative support in a multiparty presidential regime. Political Research Quarterly, v. 64, n. 2, p. 323-334, 2011. 
SANTOS, Fabiano. Em defesa do presidencialismo de coalizão. In: HERMANNS, Klaus; MORAES, Filomeno. (Orgs.). Reforma política no Brasil: realizações e perspectivas. Fortaleza: Fundação Konrad Adenauer, 2003.

STRØM, Kaare; MÜLLER, Wolfgang C.; BERGMAN, Torbjörn. Cabinets and coalition bargaining: the democractic life cycle in Western Europe. Oxford: Oxford University Press, 2008.

TAVARES, José Antonio G.; GIUSTI, Antônio. O sistema partidário na consolidação da democracia brasileira. Porto Alegre: Assembleia Legislativa do Rio Grande do Sul, 2001.

WOOLDRIDGE, Jeffrey M. Introdução à econometria: uma abordagem moderna. São Paulo: Pioneira Thomson Learning, 2006.

\section{Resumo}

Quais seriam os determinantes político-econômicos da instabilidade intracoalizão? Segundo Abranches (2014), essa instabilidade seria determinada pela força de atração presidencial, a qual é motivada por fatores políticos e macroeconômicos. Assim, o objetivo deste artigo é verificar empiricamente no Brasil a relação entre os fatores da força de atração presidencial e o apoio parlamentar da coalizão. Foram realizadas análises com dados em painel de 1995 a 2014, por meio de métodos lineares (efeitos fixos/aleatórios) e GMM. Observou-se que a diminuição do PIB causa diminuição do apoio parlamentar, bem como uma maior popularidade presidencial causa maior disciplina da coalizão. A relação entre apoio parlamentar e inflação não foi confirmada. Além disso, ressalta-se as tendências de oscilações das variáveis e sua coincidência com a ocorrência de crises políticas. Os resultados apontam a influência de fatores político-econômicos sobre o apoio parlamentar da coalizão, corroborando algumas proposições de Abranches.

Palavras-chave: presidencialismo de coalizão; ciclos; instabilidade; dados em painel.

\section{Abstract}

What would be the political and economic determinants of coalitional instability? According Abranches (2014) this instability would be 
determined by the presidential attraction force, which is motivated by political and macroeconomic factors. Therefore, the objective of this paper is empirically verify in Brazil the relationship between factors of the presidential attraction force and the parliamentary support of coalition. Analyzes were performed with panel data from 1995 to 2014, using linear methods (fixed effects and random effects) and GMM regressions. It was observed that the decrease of GDP causes decrease of the parliamentary support, as well as a greater presidential approval rating cause greater discipline of the coalition. The relation between parliamentary support and inflation has not been confirmed. In addition, we highlight the tendency of oscillations of the variables and their coincidence with the political crises occurrence. The results point to the influence of economic and political factors on the parliamentary support of the coalition, corroborating some Abranches' propositions.

Keywords: coalitional presidentialism; cycles; instability; panel data.

Recebido em 7 de agosto de 2016.

Aprovado em 7 de agosto de 2017. 